\title{
A POLÍTICA NACIONAL DOS RESÍDUOS SÓLIDOS E OS MUNICÍPIOS BRASILEIROS: DESAFIOS E POSSIBILIDADES
}

\section{THE NATIONAL SOLID WASTE POLICY AND THE BRAZILIAN MUNICIPALITIES: CHALLENGES AND POSSIBILITIES}

\author{
Janaína Rigo Santin ${ }^{1}$ \\ Maristela Pedrini ${ }^{2}$ \\ Rafaela Comiran ${ }^{3}$
}

\section{Resumo}

A pesquisa tem como problema a produção desenfreada e em grande quantidade de resíduos sólidos, que acabam por não ser destinados corretamente, o que causa um grande impacto ambiental. Pelo método dedutivo, tencionou-se analisar quais as soluções jurídicas para questão, bem como encontrar soluções para fomentar o consumo consciente e sustentável, aliados à correta destinação e tratamento do lixo. Conclui-se que, com a criação da Política Nacional de Gestão Integrada de Resíduos Sólidos, todos os municípios, dentro de suas competências, têm a oportunidade de fazer frente à problemática da produção, tratamento e destinação do lixo. Nesse sentido, grande parte das municipalidades brasileiras já elaboraram seus planos municipais de gestão dos resíduos sólidos, de forma isolada ou consorciada, sendo os consórcios importante solução para a falta de estrutura e escassez financeira dos diferentes municípios situados no País.

Palavras-chave: consórcios, meio ambiente, município, resíduos sólidos, sustentabilidade.

\begin{abstract}
The research problem is the unrestrained production and in large amount of solid waste, that end up not being destined correctly, which causes a great environmental impact. Under the deductive method, it was intended to analyse the legal solutions for this issue, as well as to find solutions to promote conscious and sustainable consumption, together with the correct disposal and treatment of waste. It is concluded that, with the creation of the National Integrated Solid Waste Management Policy, all municipalities, within their competencies, have
\end{abstract}

\footnotetext{
${ }^{1}$ Pós-Doutorado em Direito Administrativo pela Universidade de Lisboa, Portugal, com bolsa CAPES, pelo período de 8 meses (2011). Professora Titular I da Universidade de Passo Fundo, nas disciplinas de direito municipal, direito urbanístico e direito das obrigações. Professora da Universidade de Caxias do Sul, das disciplinas de direito administrativo e direito constitucional. Faz parte do corpo docente permanente do Mestrado em Direito e do Mestrado e Doutorado em História da Universidade de Passo Fundo. Professora da Graduação e Pós-Graduação lato sensu da Faculdade de Direito da Universidade de Passo Fundo. Professora convidada do Mestrado em Ciências Jurídicas-Econômicas e Desenvolvimento e do Mestrado em Governação e Gestão Pública da Universidade Agostinho Neto, em Luanda, Angola-África. E-mail: janainars@upf.br

2 Doutorado em Educação (PUCRS - 2009) na Linha de pesquisa Ensino e Educação de Professores. Estágio doutoral na Faculdade de Psicologia e Ciências da Educação da Universidade do Porto - Portugal (Agência Financiadora - CAPES). Docente do Centro de Ciências Sociais e da Educação do Campus da Região dos Vinhedos da Universidade de Caxias do Sul. Diretora do Campus Universitário de Guaporé - RS, da Universidade de Caxias do Sul. E-mail: mpedrini@ucs.br

3 Aluna da Faculdade de Direito da Universidade de Passo Fundo. Bolsista FAPERGS do projeto de pesquisa: O Estatuto da Cidade e a Gestão Democrática Municipal, vinculado ao Mestrado em Direito da Universidade de Passo Fundo. E-mail: 150438@upf.br
} 
the opportunity to face the problems of waste production, treatment and disposal. In this sense, most Brazilian municipalities have already prepared their municipal plans for the management of solid waste in an isolated or consortium manner, and the consortia are an important solution to the lack of structure and financial scarcity of the different municipalities located in the country.

Keywords: Consortiums, environment, municipality, solid waste, sustainability. 


\section{INTRODUÇÃO}

Debate-se nesta pesquisa, a partir do método dedutivo e por meio de revisão bibliográfica e análise da legislação brasileira em vigor, como as ações ou omissões do ser humano têm causado grande degradação no equilíbrio ambiental. A preocupação do artigo focaliza a produção desenfreada e em grande quantidade de resíduos sólidos, que acabam por não serem destinados corretamente, o que gera um grande impacto ambiental tanto para o meio biótico quanto para o meio abiótico.

Em face das grandes discussões a respeito da contaminação do solo, da água e da atmosfera pela má destinação dos resíduos sólidos, agravada neste novo século ante ao aumento da produção e do consumo humanos, constata-se que a capacidade para lidar com o lixo resultante deste processo é inversamente proporcional a sua produção e descarte. Assim, objetiva-se estudar de que forma a política nacional dos resíduos sólidos poderá trazer alternativas para os municípios brasileiros combaterem tais práticas e reverter estes agravos à situação, com soluções para fomentar o consumo consciente e sustentável, bem como para a correta destinação e tratamento do lixo produzido sem o suporte da sustentabilidade ambiental. E nesse intuito, constata-se que o Plano Diretor municipal é o principal instrumento de política urbana na correção das distorções urbanísticas históricas das cidades brasileiras, a guiar o correto uso do solo, da água e do ar no meio urbano.

Com a criação da Lei $n^{\circ}$ 12.305/2010, conhecida como Política Nacional de Resíduos Sólidos, é que se deu mais importância ao elemento popularmente conhecido como lixo, causador de tanta desgraça ambiental pela sua incorreta destinação. Um dos principais instrumentos previstos na novel legislação é a implantação de um Plano de Gestão Integrada de Resíduos Sólidos em cada Município, para que se regule o bom funcionamento do processo de descarte do lixo até a sua destinação final.

Entende-se por resíduos sólidos todos os restos sólidos ou semi-sólidos que resultam das atividades desenvolvidas pelo ser humano ou resultantes das ações e/ou interações de animais e da própria natureza. São considerados descartáveis, tendo em vista não apresentarem utilidade direta na situação em que foram gerados, portanto poderão ser reaproveitados em outras ações ou descartados. Segundo a Associação Brasileira das Normas Técnicas (NBR10004:2004), ${ }^{4}$

\footnotetext{
${ }^{4}$ A Associação Brasileira de Normas Técnicas (ABNT) editou um conjunto de normas para padronizar, em âmbito nacional, a classificação dos resíduos quanto aos seus potenciais ao meio ambiente e à saúde
} 
Resíduos nos estados sólido e semi-sólido, que resultam de atividades de origem industrial, doméstica, hospitalar, comercial, agrícola, de serviços e de varrição. Ficam incluídos nesta definição os lodos provenientes de sistemas de tratamento de água, aqueles gerados em equipamentos e instalações de controle de poluição, bem como determinados líquidos cujas particularidades tornem inviável o seu lançamento na rede pública de esgotos ou corpos de água, ou exijam para isso soluções técnica e economicamente inviáveis em face à melhor tecnologia disponível. (BRASIL, 2004)

Entram nessa contextualização os diferentes municípios, tanto de grande porte sobre aspectos populacional, infraestrutura, dimensões territoriais e financeiro, como aqueles de pequeno porte, mas que necessitam igualmente de uma gestão de resíduos sólidos adequada. Entretanto, a implantação de um plano de gestão de resíduos sólidos requer recursos estruturais e financeiros, coisas que um pequeno município não é capaz de arcar sozinho. Diante disso, como uma proposta de solução para este problema tem-se os chamados consórcios municipais, para que grupos de municípios possam formular, executar e gerir um plano compartilhado de seus recursos e estruturas, com vistas a contribuir, por fim, para a sustentabilidade do meio ambiente para as presentes e futuras gerações. Como afirma Leff (2011, p. 405):

Os propósitos da sustentabilidade implicam a reconstrução do mundo a partir de diversos projetos de civilização que foram construídos e sedimentados na história. A racionalidade ambiental é uma utopia forjadora de novos sentidos existenciais; traz consigo uma ressignificação na história, a partir dos limites e das potencialidades da condição humana, da natureza e da cultura.

Nesse sentido, a Política Nacional de Resíduos Sólidos constitui-se em instrumento que regulamenta e potencializa uma gestão de resíduos com vistas à sustentabilidade e à preservação ambiental enquanto condição essencial para a sobrevivência humana no planeta.

\section{MEIO AMBIENTE E SUA RELAÇÃO COM A CONSTITUIÇÃO FEDERAL DE 1988}

O desenvolvimento urbano e social tem sido discutido há anos, sempre com vistas a um desenvolvimento sustentado, e não sustentável. Foi nas últimas décadas do século XX que o foco desta discussão passou a trazer um novo olhar, a partir da conciliação do crescimento econômico e urbano com a proteção dos ecossistemas.

pública, para que possam ser gerenciados adequadamente. São elas: NBR 10004 - Resíduos Sólidos; NBR 10005 - Lixiviação de Resíduos; NBR 10006 - Solubilização de Resíduos; NBR 10007 - Amostragem de Resíduos. Para maiores informações ver (ABNT, 2017). 
Assim, o cuidado com o meio ambiente, iniciado nas décadas de 1970 e 1980 e evidenciado após a Constituição Federal de 1988, teve no século XXI um maior destaque, momento em que o problema ecológico tornou-se uma preocupação universal. Tendo em vista as novas tecnologias da informação, hoje é possível se estar informado em tempo real de todas as terríveis agressões que o ser humano vem causando, historicamente, ao meio ambiente, bem como observar como essa degradação se agravou nas primeiras décadas deste século. Pode-se citar os vazamentos de óleo no mar (TRAGÉDIA, 2010); a tragédia do rompimento da barragem em Mariana, em Minas Gerais (BARRAGEM, 2015); os problemas do descarte do lixo nas águas, capaz de formar "ilhas de plástico e lixo" (ILHAS, 2014), dentre outros.

Partindo de uma visão materialista, a sociedade moderna é a razão do desastre e do caos ambiental no mundo. Conforme Fiorindo Davi Grassi (1995, p. 12) "por questão de sobrevivência, está chegando o momento de nos preocuparmos com esse mundo desgastado durante seus quatro e meio bilhões de anos de existência".

A Lei de Política Nacional do Meio Ambiente (Lei no 6.938, de 31 de agosto de 1981) foi a primeira a conceituar, no seu artigo 3, inciso I, o que seria "meio ambiente", definindo-o como "o conjunto de condições, leis, influências e interações de ordem física, química e biológica, que permite, abriga e rege a vida em todas as formas". Trata-se do lugar onde vivem os seres vivos, com todas as suas características geofísicas. Ou seja, meio ambiente não é apenas a natureza ou os recursos naturais, mas também envolve tudo aquilo que permite a sobrevivência das espécies. Para José Afonso da Silva (2004, p. 20) a definição de meio ambiente é "abrangente de toda a natureza, o artificial e original, bem como os bens culturais correlatos, compreendendo, portanto, o solo, a água, o ar, a flora, as belezas naturais, o patrimônio histórico, artístico, turístico, paisagístico e arquitetônico".

Tendo em vista tantas catástrofes ambientais, tornou-se evidente que alguma coisa havia de ser feita para preservar a vida das gerações presentes bem como das futuras gerações, pois tantas calamidades acabariam por devastar tudo o que há de mais precioso para os seres vivos: o meio ambiente e as condições de sobrevivência no planeta. A legislação brasileira ocupou-se em garantir esse direito fundamental dos cidadãos, positivando numerosas normas protetivas em relação ao meio ambiente. Nesse sentido, importa ressaltar que a Constituição Federal de 1988 dedicou especial atenção ao tema, reservando um capítulo do texto constitucional para tratar exclusivamente do meio ambiente (artigo 225, seus incisos e parágrafos). 
Como afirma o autor, na história do constitucionalismo brasileiro a Constituição de 1988 foi "a primeira a tratar deliberadamente da questão ambiental" e ficou conhecida para alguns como a Constituição Verde. (SILVA, 2004, p. 46) Em seu Capítulo VIII, Título VI, positivou no artigo 225 uma completa abordagem a respeito do meio ambiente: "Art. 225.- Todos têm direito ao meio ambiente ecologicamente equilibrado, bem de uso comum do povo e essencial à sadia qualidade de vida, impondo-se ao poder público e à coletividade o dever de defende-lo e preservá-lo para as presentes e futuras gerações."

Percebe-se aqui o caráter geral da norma. Para as presentes e futuras gerações um ambiente ecologicamente equilibrado é de vital importância, e fica a cargo do poder público e da coletividade preservá-lo e, assim, defender aquilo que existe na atualidade, pois a legislação incide no que existe e prevê a criação de reservas legais e de preservação para o futuro. Todas as demais normas infraconstitucionais, políticas públicas e decisões jurisdicionais devem estar baseadas na Constituição Federal, norma máxima do país e diretriz para a atuação dos três poderes da República.

Já nos parágrafos e incisos do artigo 225, a Magna Carta fala sobre a responsabilidade do poder público para garantir a efetividade desse direito:

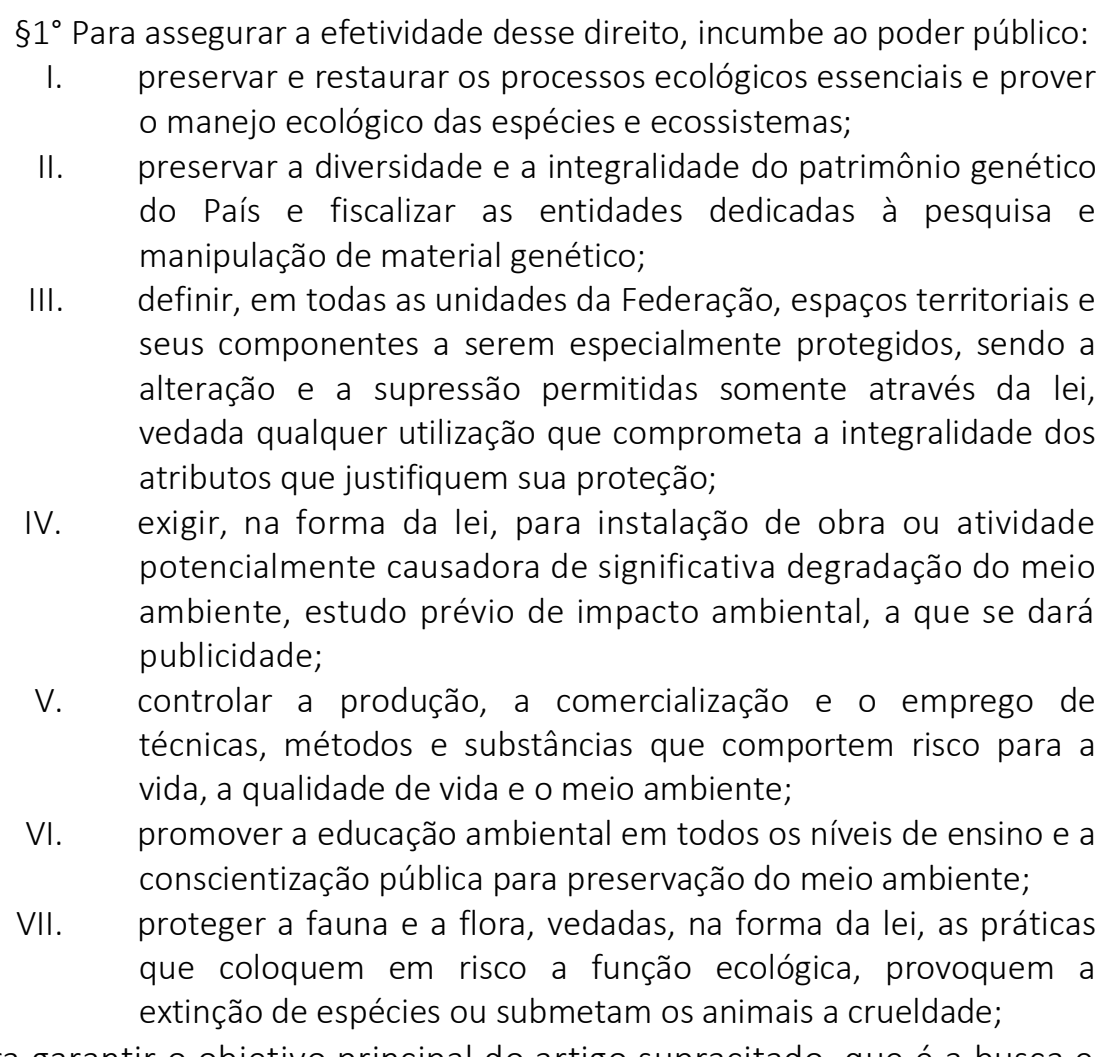

Veja-se que, para garantir o objetivo principal do artigo supracitado, que é a busca e manutenção de um meio ambiente sustentável, o inciso III estabelece que as unidades da 
Federação possam ter alguns de seus espaços protegidos, os quais devem restar intocáveis para a busca do meio ambiente ecologicamente equilibrado. Para manter esses espaços é preciso fiscalização adequada acerca de atividades que possam causar degradação do meio ambiente, a qual caberá às três entidades federativas. Por sua vez, o estudo prévio referido no inciso IV é feito para analisar as possíveis consequências que determinado projeto pode ocasionar ao meio ambiente.

Conforme a Resolução n01 de 1986 do Conama (Conselho Nacional do Meio Ambiente):

Art. 1.- Para efeito desta Resolução, considera-se impacto ambiental qualquer alteração das propriedades físicas, químicas e biológicas do meio ambiente, causada por qualquer forma de matéria ou energia resultante das atividades humanas que, direta ou indiretamente afetam:

I. a saúde, a segurança e o bem-estar da população;

II. as atividades sociais e econômicas;

III. a biota;

IV. as condições estéticas e sanitárias do meio ambiente;

V. a qualidade dos recursos ambientais.

Para dimensionar o impacto ambiental de empreendimentos resultantes da atividade humana será necessário formular o EIA/RIMA (estudo de impacto ambiental e respectivo relatório de impacto ambiental), o qual deverá descrever as seguintes atividades técnicas (art. 6 da Resolução n. 01/86 do Conama): diagnóstico ambiental da área de influência do projeto, considerando o meio físico, biológico e socioeconômico; análise dos impactos ambientais do projeto e de suas alternativas; definição das medidas mitigadoras dos impactos negativos e a elaboração do programa de acompanhamento e monitoramento.

E a respectiva Resolução, em seu artigo 2, determina que o EIA/RIMA deverá ser realizado principalmente para as seguintes atividades:

I. Estradas de rodagem com duas ou mais faixas de rolamento;

II. Ferrovias;

III. Portos e terminais de minério, petróleo e produtos químicos;

IV. Aeroportos, conforme definidos pelo inciso 1, artigo 48, do Decreto-Lei no 32, de 18.11.66;

V. Oleodutos, gasodutos, minerodutos, troncos coletores e emissários de esgotos sanitários;

VI. Linhas de transmissão de energia elétrica, acima de 230KV;

VII.Obras hidráulicas para exploração de recursos hídricos, tais como: barragem para fins hidrelétricos, acima de $10 \mathrm{MW}$, de saneamento ou de irrigação, abertura de canais para navegação, drenagem e irrigação, retificação de cursos d'água, abertura de barras e embocaduras, transposição de bacias, diques [...].

Por sua vez, o parágrafo $2^{\circ}$ do artigo 225 da Constituição trata da responsabilidade dos mineradores no momento de sua exploração, pois se faz necessária a autorização ou permissão 
para explorar. Após esse processo, o órgão competente fará a vistoria para averiguar os danos, e fica este responsável por tomar as providências necessárias para a recuperação. ${ }^{5} \mathrm{O}$ parágrafo $3^{\circ}$ refere-se aos crimes contra o meio ambiente e alerta sobre as possíveis penalidades. ${ }^{6}$ Os parágrafos $4^{\circ}$ e $5^{\circ}$ tratam do patrimônio público do Estado e do País, regulando o uso e a exploração dos recursos naturais advindos destas propriedades ${ }^{7}$. E, por fim, tem-se o parágrafo $6^{\circ}$, que se refere à localização das usinas operadas por reatores nucleares, ou seja, qualquer estrutura que possua combustível nuclear, sendo que estas deverão se estabelecer em localizações definidas por lei federal, sem exceções. ${ }^{8}$

Ainda na Constituição Federal existem dois artigos que tratam do uso do solo nas cidades e da política urbana, regulamentados posteriormente pela Lei 10.257 de julho de 2001, conhecida como Estatuto da Cidade. Os artigos 182 e 183 são de suma importância, pois abordam a respeito da organização do espaço urbano relacionado à melhores condições de vida para a população. É o que se verá a seguir.

\section{A POLÍTICA URBANA E O ESTATUTO DA CIDADE}

Rousseau (2001), em sua obra "Discurso sobre a origem da desigualdade", revela o início do processo de desigualdade social.

Nesse estado, as coisas poderiam ter ficado iguais, se os talentos fossem iguais, e se, por exemplo, o emprego do ferro e o consumo dos alimentos tivessem feito sempre uma balança exata: mas, a proporção que ninguém mantinha foi logo rompida: o mais forte fazia mais tarefa; o mais destro tirava melhor partido da sua; o mais engenhoso encontrava meios de abreviar o trabalho; o lavrador tinha mais necessidade de ferro, ou o ferreiro mais necessidade de trigo; e trabalhando igualmente, um ganhava muito, enquanto outro mal podia viver (ROUSSEAU, 2001, p. 107-108).

Ou seja, para Rousseau o indivíduo primitivo é totalmente generoso, porém, ao se relacionar com os demais, em uma sociedade, comete o erro de praticar a desigualdade. Ele

\footnotetext{
${ }^{5} \S 2^{\circ}$ Aquele que explorar recursos minerais fica obrigado a recuperar o meio ambiente degradado, de acordo com a solução técnica exigida pelo órgão público competente, na forma da lei.

${ }^{6} \S 3^{\circ}$ As condutas e atividades consideradas lesivas ao meio ambiente sujeitarão os infratores, pessoas físicas ou jurídicas, sanções penais e administrativas, independente da obrigação de reparar o dano.

${ }^{7}$ § 4으 A Floresta Amazônica brasileira, a Mata Atlântica, a Serra do Mar, o Pantanal Mato-Grossense e a Zona Costeira são patrimônio nacional, e sua utilização far-se-á, na forma da lei, dentro de condições que assegurem a preservação do meio ambiente, inclusive quanto ao uso dos recursos naturais. §5o São indisponíveis as terras devolutas ou arrecadadas pelos Estados, por ações discriminatórias, necessárias à proteção dos ecossistemas naturais

${ }^{8} \S 60$ As usinas que operem com reator nuclear deverão ter sua localização definida em lei federal, sem o que não poderão ser instaladas.
} 
indica em sua obra que a desigualdade praticada vai desde um simples ciúme de um relacionamento até a formação da propriedade privada como uma base econômica.

Realizando um paralelo frente ao entendimento de Rousseau para o Brasil, em especial no final do século $X X$, devido à grande massa populacional que migrou do campo para a área urbana, fez-se necessário uma intervenção estatal para reduzir as desigualdades no meio urbano. Em meio a cidades caracterizadas por serem desiguais, consequência do crescimento desenfreado e da falta de estrutura e planejamento para as classes pobres que vinham buscar emprego e melhoria de suas condições de vida, observou-se que, de um lado, prevalece a pobreza e a cidade informal, e do outro lado, na cidade formal, na qual há áreas planejadas com estrutura econômica e infraestrutura adequadas para disponibilizar uma vida digna e saudável para sua população. Assim, o que se pode presenciar no Brasil são, em sua maioria, cidades profundamente desiguais.

Na busca por cidades mais justas e economicamente viáveis, capazes de compatibilizar proteção ambiental, crescimento econômico e justiça social, fora acrescentado o capítulo da política urbana na Constituição Federal de 1988, fruto de grandes mobilizações do movimento pró moradia em busca de melhores condições de vida para toda a população nas cidades brasileiras. E, a partir disso, a lei ordinária federal de n. 10.257 de julho de 2001, também denominada Estatuto da Cidade, foi elaborada. Ela regulamenta os artigos 182 e 183 da Constituição Federal, que tratam da política urbana:

Art. 182. A política de desenvolvimento urbano, executada pelo poder público municipal, conforme diretrizes gerais fixadas em lei, tem por objetivo ordenar o pleno desenvolvimento das funções sociais da cidade e garantir o bem-estar de seus habitantes.

$\S 1$ - - O plano diretor, aprovado pela Câmara Municipal, obrigatório para cidades com mais de vinte mil habitantes, é o instrumento básico da política de desenvolvimento e de expansão urbana.

$\S 2$ - - A propriedade urbana cumpre sua função social quando atende às exigências fundamentais de ordenação da cidade expressas no plano diretor.

§ 3ㅇ- - As desapropriações de imóveis urbanos serão feitas com prévia e justa indenização em dinheiro.

$\S 4$ o - É facultado ao poder público municipal, mediante lei específica para área incluída no plano diretor, exigir, nos termos da lei federal, do proprietário do solo urbano não edificado, subutilizado ou não utilizado que promova seu adequado aproveitamento, sob pena, sucessivamente, de: I - parcelamento ou edificação compulsórios; II - imposto sobre a propriedade predial e territorial urbana progressivo no tempo; III desapropriação com pagamento mediante títulos da dívida pública de emissão previamente aprovada pelo Senado Federal, com prazo de 
resgate de até dez anos, em parcelas anuais, iguais e sucessivas, assegurados o valor real da indenização e os juros legais.

O supracitado artigo determina que os municípios tenham a responsabilidade de conferir a sua população uma sadia qualidade de vida, por meio de uma política urbana adequada às necessidades populacionais, tendo em vista a preservação do meio ambiente para as presentes e futuras gerações. Como se nota, o legislador constituinte de 1988 preocupou-se principalmente com as funções sociais da propriedade e da cidade, as quais os espaços urbanos devem cumprir.

O artigo ainda salienta a importância do Plano Diretor municipal, como principal instrumento de concretização desta novel política urbana. ${ }^{9}$ Nas palavras de Carlos Sérgio Gurgel da Silva (2013), "com a aprovação do plano diretor e sua entrada em vigor, o Poder Público municipal poderá corrigir uma série de distorções urbanísticas presentes no território do município, algumas delas históricas, além de melhor planejar as ocupações futuras e seus múltiplos usos".

Vê-se ainda a exigência feita aos proprietários de solos urbanos para que usem de forma adequada as suas propriedades, evitando o descumprimento de sua função social a partir da subutilização, não utilização ou não edificação. Acaso desrespeitada a função social, tais imóveis urbanos correm o risco de parcelamento ou edificação compulsórios, imposto predial e territorial urbano progressivo e desapropriação com pagamento em títulos. (SANTIN; LEIDENS, 2006)

Por sua vez, o artigo 183 da Carta Magna refere-se ao direito de usucapião especial constitucional, a ser deferido tanto para homens quanto para mulheres, sem distinção por gênero, desde que não sejam proprietários de outro imóvel. ${ }^{10}$ Assim, se utilizarem para si ou sua família de um imóvel urbano por cinco anos, sem interrupções, não sendo este imóvel do poder público, poderão garantir o seu domínio e propriedade pela prescrição aquisitiva. ${ }^{11}$

Já no que se trata à lei federal que veio para regulamentar o capítulo da política urbana na Constituição Federal de 1988, Lei n. 10.257/2001, denominada Estatuto da Cidade, cabe

\footnotetext{
9 Para maior aprofundamento sobre o papel do Plano Diretor nas cidades brasileiras ver: (SANTIN; SANTOS, 2016).

${ }^{10}$ Para maior aprofundamento sobre a usucapião especial urbano ver: (SANTIN; SIGNOR, 2016).

11 Art. 183. Aquele que possuir como sua área urbana de até duzentos e cinquenta metros quadrados, por cinco anos, ininterruptamente e sem oposição, utilizando-a para sua moradia ou de sua família, adquirir-Ihe-á o domínio, desde que não seja proprietário de outro imóvel urbano ou rural. §1으 - O título de domínio e a concessão de uso serão conferidos ao homem ou à mulher, ou a ambos, independentemente do estado civil. §2으 - Esse direito não será reconhecido ao mesmo possuidor mais de uma vez. § 3o - Os imóveis públicos não serão adquiridos por usucapião.
} 
salientar que teve sua origem como um Projeto de Lei apresentado pelo então senador Pompeu de Sousa, em 1988. No ano seguinte, foi apresentado ao Senado onde foi aprovado e encaminhado à Câmara Federal. Em 1999, o deputado e ex-senador Inácio Arruda tomou o cargo de Presidente da Comissão de Desenvolvimento Urbano Interior e deu andamento ao Estatuto, que só foi aprovado e sancionado em 2001, pelo então presidente Fernando Henrique Cardoso. (SANTIN, 2003)

O Estatuto instituiu normas que acondicionam o uso do solo urbano visando a sua função social, o bem-estar coletivo, a segurança e também um meio ambiente ecologicamente equilibrado. A política urbana, tratada nos artigos 182 e 183 da Carta Maior, refere-se ao pleno desenvolvimento das funções sociais da cidade, bem como o bem-estar de quem a habita. Para alcançar o objetivo da referida política, a Lei 10.257/01 estabelece algumas diretrizes gerais em seu artigo $2^{\circ}$. Resumidamente, são elas:

a. função social das cidades e sustentabilidade: garante a todos direitos básicos de acesso à terra urbana, moradia, saneamento ambiental, infraestrutura, transporte público, trabalho e lazer;

b. gestão democrática: compreende a garantia da participação popular tanto individual quanto em associações representativas para a formulação e acompanhamento dos projetos de desenvolvimento urbano;

c. organização e controle do uso solo urbano, impedindo usos incompatíveis; d) Integração das atividades urbanas e rurais;

d. obediência aos padrões de sustentabilidade na produção e consumo de bens e serviços, ajustados com os limites e à realidade do Município;

e. simplificação da legislação de parcelamento, uso e ocupação do solo urbano, reduzindo, por exemplo, índices urbanísticos de fracionamento do solo;

f. tratamento prioritário às obras e edificações de infraestrutura de energia, telecomunicações, abastecimento de água e saneamento, entre outros.

Ao mencionar, no artigo acima, às "funções sociais da cidade", pode-se incluir além do desenvolvimento sustentável e da obediência às prescrições ambientais as necessidades de saneamento básico, moradias, lazer, trabalho, reduzindo as desigualdades entre o espaço urbano e rural, entre os bairros e entre os cidadãos dos municípios. Trata-se, em verdade, de se buscar a sustentabilidade das cidades brasileiras, que precisam crescer economicamente sem deixar de preservar o meio ambiente nem tratar de forma injusta seus habitantes. 
José Carlos de Freitas (2016) faz uma abordagem de como o Estatuto pode auxiliar para se chegar ao equilíbrio ambiental tão fomentado. Segundo o autor "a Lei 10.257, de 10/07/01 incorporou expressamente as funções moradia, trabalho e lazer ao definir o direito a cidades sustentáveis (art. 2ㅇ, I). "Trata-se de superar a tradição histórica do desenvolvimento sustentado, preocupado apenas com o crescimento econômico, para um desenvolvimento sustentável. Ou seja, cidade sustentável é aquela que proporciona políticas públicas sustentáveis, protegendo e preservando o meio ambiente, evitando a utilização inadequada dos imóveis urbanos, o gerenciamento do solo, o uso inadequado da infraestrutura urbana, entre outros.

Assim, no que tange ao meio ambiente e das cidades sustentáveis, o tripé da sustentabilidade consagrado na Rio+20, que visa conciliar preservação ambiental, desenvolvimento econômico e justiça social, tornou-se um ideal a ser seguido, mas também um grande dilema, em face às dificuldades para alcançar um equilíbrio entre os conceitos. (MARTINE; ALVES, 2015) Ele existe para que as empresas o tomem como base para garantir seus lucros, visando o bem-estar da sociedade sem degradar o planeta. Seguindo os passos para o bom funcionamento do tripé, os três lados devem ter benefícios. O pilar social, que se refere ao capital humano, deve oferecer aos trabalhadores salários justos e adequados às leis trabalhistas, proporcionar também um ambiente agradável de trabalho, pensando sempre no bem-estar dos funcionários. Também precisa garantir a todos habitantes da cidade o mesmo acesso aos direitos fundamentais, independentemente do local ou região onde moram. O pilar econômico é aquele que move a sociedade, onde serão analisados aspectos ligados à produção de bens e serviços e o consumo. O pilar ambiental, que é o último passo, basta que se reduza o impacto que as empresas geram no meio ambiente. Assim, o tripé funciona e todos os lados se beneficiam. (FREITAS, 2016)

É de suma importância salientar que, para alcançar os fins da lei 10.257/2001, o seu artigo $4^{\circ}$ cita alguns instrumentos que poderão ser adotados, dentre eles os planos nacionais, regionais, estaduais e municipais de ordenação do território, assim como o planejamento em conjunto das regiões metropolitanas, aglomerações urbanas e microrregiões.

Nessa ideia de planejamento, a Política Nacional de Resíduos Sólidos exige que os municípios elaborem políticas concretas nesta área, além de fomentar uma educação ao consumo sustentável em seus munícipes, capaz de reduzir o lixo que é produzido pelos confortos da vida moderna. Sendo assim, ao pensar a questão dos municípios modernos e o chamado tratamento e destinação de resíduos sólidos, urge tratar-se do tema a partir de uma 
visão nacional, intermunicipal ou inter-regional. Este problema afeta a sadia qualidade de vida da sociedade, e com certeza já cria e criará problemas ainda maiores para as futuras gerações.

Além de poluir e degradar o meio ambiente, o lixo resulta também em graves doenças para as populações humanas, para a fauna e para a flora. E no intento de resolver esse problema pode-se utilizar de um instrumento referido no inciso I do artigo $4^{\circ}$ do Estatuto da Cidade, chamado de Plano Nacional de Resíduos Sólidos. Este será tratado mais especificadamente no item a seguir.

\section{POLÍTICA NACIONAL DE RESÍDUOS SÓLIDOS}

A Lei 12.305, de 2 de agosto de 2010, instituiu a Política Nacional de Resíduos Sólidos, dispondo sobre os princípios, objetivos, diretrizes e instrumentos a serem utilizados para alcançar os fins do referido diploma. A lei é direcionada ao gerenciamento de resíduos sólidos, incluindo os perigosos e excluindo os radioativos, pois estes são regulados por lei específica.

A Política Nacional de Resíduos Sólidos é destinada a todas as instâncias de poder (nacional, estadual, microrregional, regiões metropolitanas ou aglomerações urbanas, intermunicipal e municipal), a fim de que elaborem seus planos de gestão integrada de resíduos sólidos com vistas a atingir os objetivos descritos no seu artigo $7^{\circ} .12$

\footnotetext{
${ }^{12}$ Art. 70 São objetivos da Política Nacional de Resíduos Sólidos: I - proteção da saúde pública e da qualidade ambiental; II - não geração, redução, reutilização, reciclagem e tratamento dos resíduos sólidos, bem como disposição final ambientalmente adequada dos rejeitos; III - estímulo à adoção de padrões sustentáveis de produção e consumo de bens e serviços; IV - adoção, desenvolvimento e aprimoramento de tecnologias limpas como forma de minimizar impactos ambientais; $V$ - redução do volume e da periculosidade dos resíduos perigosos; $\mathrm{VI}$ - incentivo à indústria da reciclagem, tendo em vista fomentar o uso de matérias-primas e insumos derivados de materiais recicláveis e reciclados; VII gestão integrada de resíduos sólidos; VIII - articulação entre as diferentes esferas do poder público, e destas com o setor empresarial, com vistas à cooperação técnica e financeira para a gestão integrada de resíduos sólidos;

IX - capacitação técnica continuada na área de resíduos sólidos;

$X$ - regularidade, continuidade, funcionalidade e universalização da prestação dos serviços públicos de limpeza urbana e de manejo de resíduos sólidos, com adoção de mecanismos gerenciais e econômicos que assegurem a recuperação dos custos dos serviços prestados, como forma de garantir sua sustentabilidade operacional e financeira, observada a Lei no 11.445, de 2007; XI - prioridade, nas aquisições e contratações governamentais, para: a) produtos reciclados e recicláveis; b) bens, serviços e obras que considerem critérios compatíveis com padrões de consumo social e ambientalmente sustentáveis; XII - integração dos catadores de materiais reutilizáveis e recicláveis nas ações que envolvam a responsabilidade compartilhada pelo ciclo de vida dos produtos; XIII - estímulo à implementação da avaliação do ciclo de vida do produto; XIV - incentivo ao desenvolvimento de sistemas de gestão ambiental e empresarial voltados para a melhoria dos processos produtivos e ao reaproveitamento dos resíduos sólidos, incluídos a recuperação e o aproveitamento energético; XV estímulo à rotulagem ambiental e ao consumo sustentável.
} 
Ou seja, o Plano Nacional de Resíduos Sólidos visa à redução da produção do lixo e do descarte humano, bem como ao seu reaproveitamento. Acaso este último não seja possível, pelo menos deve ser dada uma disposição correta e não prejudicial ao meio ambiente, dentre outras medidas. O principal ponto do plano, além de implantar a logística reversa - que será esmiuçada a seguir - é também determinar que a destinação dos rejeitos siga exclusivamente para aterros sanitários.

A logística reversa é tida como um grande avanço na destinação sustentável dos resíduos sólidos no país. Consiste no fato de os fabricantes, a partir do momento que suas embalagens são descartadas, criarem uma forma de reciclá-las. Dispõe Edmilson Rodrigues da Costa um breve comentário sobre quais produtos incide a logística reversa:

a Lei da PNRS determina, em seu Artigo 33, que são obrigados a estruturar e implementar sistemas de logística reversa, mediante retorno dos produtos após o uso pelo consumidor, de forma independente do serviço público de limpeza urbana e de manejo dos resíduos sólidos, os fabricantes, importadores, distribuidores e comerciantes de agrotóxicos, pilhas e baterias, pneus, óleos lubrificantes, lâmpadas fluorescentes, de vapor de sódio e mercúrio e de luz mista e produtos eletroeletrônicos e seus componentes. (COSTA, 2016)

Assim, o que se quer é que o encarregado por comercializar e distribuir produtos geradores de resíduos fique responsável pelo seu descarte, retirando do Estado este ônus.

Por sua vez, a lei estabelece uma lista de princípios em seu art. $6^{\circ}$, para que, segundo Paulo Affonso Leme Machado (2012, p. 25), "seus aplicadores possam ter orientação eficiente e segura para a própria interpretação do texto legal e de sua regulamentação". Os princípios são os seguintes:

a. princípio da prevenção e da precaução: estão intimamente ligados ao primeiro objetivo da Política Nacional de Resíduos Sólidos, qual seja, a proteção da saúde pública e da qualidade ambiental e não geração de rejeitos;

b. princípio do poluidor pagador: consiste no ato de aquele que polui possuir a obrigação de pagar as devidas multas como consequência de seu ato;

c. princípio da responsabilidade compartilhada: a lei estabelece um ciclo de responsabilidades que engloba todos os que participaram do ciclo de vida do produto, de maneira solidária;

d. princípio da cooperação: exige a cooperação das diferentes esferas de poder, do setor empresarial e dos demais segmentos da sociedade no combate e prevenção dos riscos ambientais; 
e. princípio do protetor recebedor: assim como aquele que polui deve pagar, aquele que não polui deve ser recompensado por isso, tendo o reconhecimento tanto do Poder Público como também da coletividade, com incentivos fiscais, obtenção de selos de qualidade e sustentabilidade, etc.;

f. princípio da visão sistêmica: consiste na observação de variáveis não só ambientais, como também sociais, culturais, econômicas, tecnológicas e de saúde pública, no processo de gestão dos resíduos, as quais atuam de forma conjunta e precisam ser analisadas de maneira combinada;

g. princípio da ecoeficiência: definido por lei como a busca por compatibilizar preços competitivos com bens e serviços qualificados, capazes de satisfazer as necessidades humanas e propiciar "qualidade de vida e a redução do impacto ambiental e do consumo de recursos naturais a um nível, no mínimo, equivalente à capacidade de sustentação estimada do planeta." (2012, p. 30);

h. princípio do reconhecimento do valor do resíduo sólido reutilizável e reciclável: fornece como opções, para reduzir os resíduos sólidos, a reutilização e a reciclagem;

i. princípio do respeito às diversidades locais e regionais: a proteção do meio ambiente deve ser efetivamente feito pela União, Distrito Federal e Estados, sem exclusão de nenhuma região, com respeito ao multiculturalismo e à diversidade;

j. princípio da razoabilidade e da proporcionalidade: serão aplicados tanto para a Administração pública como para as empresas, a sociedade civil e as pessoas, procurando o lado mais objetivo da questão, adotando uma medida justa para responsabilizar os citados anteriormente;

k. princípio do direito à informação: as pessoas, por meio da facilitação de acesso às informações, podem adquirir o conhecimento da existência da Política dos Resíduos Sólidos e, a partir daí, engajar-se na separação do que pode ser reciclado e reutilizado e o que não pode, tornando, assim, a informação aberta e socializada;

I. princípio do direito da sociedade ao controle social: garante para a sociedade e entidades representativas a livre participação no processo de formulação, implementação e avaliação de todas as políticas públicas relativas à política de gestão e tratamento dos resíduos (MACHADO, 2012). 
Para que os indivíduos consigam atingir as metas da Lei 12.305/2010, são enumerados em seu artigo $7^{\circ}$ os fins e objetivos previstos para a política de redução, tratamento e adequada destinação dos resíduos sólidos no país. O Brasil, para efeito de conhecimento, foca em metas de desenvolvimento sustentável a partir do momento que reconhece a sua potencialidade econômica, sem deixar de lado a geração de emprego e renda. Dentre os quinze objetivos da lei, os principais e que devem ser frisados são os seguintes:

a. proteger a saúde pública e a qualidade ambiental: se do manejo dos resíduos sólidos resultar algum dano ambiental ou à saúde humana, caberá ao Poder Público amenizar ou cessar o dano;

b. não gerar resíduo, estimulando a adoção de padrões sustentáveis de consumo e produção de bens e serviços: não se pode acolher a ideia de que todos podem produzir livremente resíduos sólidos, sem nenhum limite;

c. valorização do catador: se refere às pessoas que se dedicam a coletar e a transportar os resíduos produzidos por toda a sociedade, as quais tem papel essencial neste processo e precisam ser valorizadas tanto social quanto economicamente ${ }^{13}$;

d. incentivo à indústria da reciclagem, à rotulagem ambiental e ao consumo sustentável;

e. quanto a resíduos perigosos, é preciso reduzir seu volume e periculosidade, bem como dedicar especial atenção à sua adequada destinação;

f. adoção, desenvolvimento e aprimoramento de tecnologias limpas;

g. gestão integrada de resíduos sólidos, com articulação e cooperação técnica e financeira entre diversos entes federativos, esferas de poder e destes com o setor empresarial;

h. capacitação técnica continuada daqueles que labutam na área dos resíduos sólidos;

\footnotetext{
${ }^{13}$ Importante a seguinte nota do site do Ministério do Meio Ambiente no Brasil: "No Brasil, a estimativa é de que existam 600 mil catadores de materiais recicláveis, que, além de garantir o sustento de suas famílias com a separação dos resíduos, prestam um importante serviço ambiental para toda a sociedade, na medida em que são os maiores responsáveis pela reciclagem no País. Atualmente, grande parte desses trabalhadores estão nos lixões e aterros espalhados pelo Brasil. Com o advento da Lei 12.305/2010 (PNRS), ficou proibido o exercício dessas atividades nos lixões. É preciso então integrá-los na cadeia da reciclagem e, dessa forma, promover a cidadania desses trabalhadores com inclusão social e geração de emprego e renda." (BRASIL, 2017)
} 
i. regularidade, continuidade, funcionalidade e universalização da prestação dos serviços de limpeza urbana e manejo de resíduos, adotando-se mecanismos gerenciais que assegurem a sustentabilidade operacional e financeira, observada a lei 11.445/2007;

j. nas licitações, deve ser priorizada aquisição de produtos reciclados e recicláveis, bens, serviços e obras compatíveis com padrões de consumo sustentável ${ }^{14}$;

k. estímulo à implementação da avaliação do ciclo de vida do produto;

I. incentivo ao desenvolvimento de sistemas de gestão ambiental e empresarial voltados para a melhoria dos processos produtivos e ao reaproveitamento dos resíduos sólidos, incluídos a recuperação e o aproveitamento energético.

Vale salientar que esta política pode e deve ser aplicada nos âmbitos nacional, estadual, microrregional, intermunicipal e municipal. Dentro destes âmbitos, quem deve estar submetido à lei são as pessoas físicas e jurídicas, tanto de direito público como do privado, que se consagrem responsáveis - direta ou indiretamente - pela geração dos resíduos. No próximo item será analisado como os municípios estão se ajustando aos requisitos do Plano Nacional de Resíduos Sólidos.

\section{POLÍTICA DE RESÍDUOS SÓLIDOS NOS MUNICÍPIOS BRASILEIROS}

É um requisito essencial dos municípios brasileiros e do Distrito Federal que executem um Plano Municipal de Gestão Integrada de Resíduos Sólidos, para que possam ter acesso aos recursos que a União disponibiliza para este fim, o que serve como um incentivo para a gestão integrada dos resíduos. O Ministério do Meio Ambiente, quando apresenta o Plano Nacional de Resíduos Sólidos, explica:

O Plano de Gerenciamento de Resíduos Sólidos (PGRS) é o instrumento que define o conjunto de informações e estratégias integradas de gestão, destinados a normatizar os procedimentos operacionais de gerenciamento de resíduos sólidos, contemplando os aspectos referentes à geração, à segregação, ao acondicionamento, à identificação, à coleta, ao transporte, ao armazenamento, ao tratamento e à disposição final em conformidade com a legislação sanitária e ambiental (Resolução da Diretoria Colegiada - RCD no 02/2003 da Agência Nacional de Vigilância Sanitária). [...] Conforme a PNRS, o plano de gerenciamento de resíduos sólidos deve conter, dentre outras informações:

i. descrição do empreendimento ou atividade;

\footnotetext{
${ }^{14}$ Sobre licitações sustentáveis, interessante a análise do seguinte material, da Advocacia Geral da União: (CARVALHO et al, 2016).
} 
ii. diagnóstico dos resíduos sólidos gerados ou administrados, contendo a origem, o volume e a caracterização dos resíduos, incluindo os passivos ambientais a eles relacionados;

iii. explicitação dos responsáveis por cada etapa do gerenciamento de resíduos sólidos;

iv. definição dos procedimentos operacionais relativos às etapas do gerenciamento de resíduos sólidos sob responsabilidade do gerador;

v. ações preventivas e corretivas a serem executadas em situações de gerenciamento incorreto ou acidentes;

vi. metas e procedimentos relacionados à minimização da geração de resíduos sólidos

vii. medidas saneadoras dos passivos ambientais relacionados aos resíduos sólidos; periodicidade de sua revisão (BRASIL, 2011a, p. $35 ; 36 ; 41)$.

Assim sendo, em análise prática do guia de elaboração, um Plano Municipal de Resíduos Sólidos deve conter:

a. uma breve introdução apresentando os seus objetivos, como a implementação de condições adequadas para o gerenciamento dos resíduos sólidos daquele município ou região, bem como explicitar como irá aderir aos princípios da minimização da geração, da reutilização, da reciclagem, do tratamento e da disposição final adequada;

b. apresentar como o Plano foi desenvolvido, fornecendo as legislações usadas como referência;

c. comprovar que possibilitou a gestão democrática da gestão de resíduos, com ampla participação popular no momento de elaboração, discussão e aprovação do seu plano de resíduos;

o documento deve ser baseado na Lei supracitada 12.305/2010, que explana os requisitos mínimos necessários para a elaboração do plano em seu artigo $9^{\circ}$ como, por exemplo: diagnóstico da situação dos resíduos sólidos gerados naquele território; possíveis áreas para a disposição final adequada dos resíduos; possibilidade de consórcios municipais para implantação de um plano intermunicipal; os tipos de resíduos sólidos produzidos naquele município; existência ou não de um serviço público de limpeza e de manejo dos resíduos; indicar como se dá o transporte do gerenciamento dos resíduos; definir as responsabilidades para a sua implantação e a questão da lógica reversa; enfatizar que o plano será fonte de emprego e renda; comprovar que houve a participação popular do poder público local na sua elaboração e posterior aplicação e fiscalização; indicar o período de revisão do Plano; 
d. é necessário também que o plano exponha as possíveis doenças ocasionadas pela não gestão dos resíduos sólidos, como: peste, febre amarela, dengue, toxoplasmose, leishmaniose, salmonelose, teníase, leptospirose, cólera e febre tifoide;

e. deve-se fazer um conceito geral a respeito das características físicas dos resíduos, que podem ser classificadas em: geração per capita; composição gravimétrica; peso específico aparente; teor de umidade e compressividade, apresentando também, como informação para a comunidade, as cores de separação do lixo bem como os símbolos de identificação dos grupos de resíduos;

f. chegando ao final, deve-se determinar os custos para a implantação do plano, abrangendo os custos referentes à coleta e transporte, de destinação e disposição, custos indiretos com a fiscalização, combate a vetores, administrativos, relativos à amortização e depreciação de investimentos;

g. e, por fim, apresentar iniciativas relevantes, como: as ações de cooperativas de catadores; projetos desenvolvidos com a parceria de ONGs e outras associações da sociedade civil; campanhas e projetos com políticas ambientais e sociais; ações em escolas e bairros, dentre outras (BRASIL, 2011b, p. 51-53).

Ou seja, resumindo o que foi exposto até o presente momento, o plano deve expor a divisão de responsabilidades para a sua implementação e operacionalização, estabelecendo as etapas de desenvolvimento e as atividades previstas. Além disso, também determina que deve haver uma integração entre o Plano de Saneamento Básico e os planos de água, esgoto, drenagem urbana e resíduos sólidos.

Entretanto, a lei da Política Nacional dos Resíduos Sólidos dispõe sobre outros critérios práticos, como o fato de que os municípios com menos de vinte mil habitantes poderem optar por fazer um Plano de Gestão Integrada de Resíduos Sólidos (PGIRS) com conteúdo simplificado. Porém, isso não será aplicado se estes municípios integrarem áreas de interesse turístico ou se forem inseridos na área de influência de empreendimentos ou atividades causadoras de grande impacto ambiental e cujo território abranja, total ou parcialmente, Unidades de Conservação. ${ }^{15}$

${ }^{15}$ O Instituto Brasileiro de Geografia e Estatística - IBGE (BRASIL, 2013) divulgou uma pesquisa a respeito de algumas informações consideradas básicas aos municípios brasileiros sobre o assunto, que foi realizada em 5.570 municípios e mais o Distrito Federal, que se refere ao ano de 2013, encontrada no site do IBGE (Tabela 67), dispondo que: a) dos municípios de até 5.000 habitantes, apenas $32,1 \%$ deles possuem um PGIRS; b) Dos municípios de 5.001 até 10.000 habitantes, 26,9\% deles possuem um PGIRS; 
A Lei 12.305/2010 estabelece que alguns municípios serão priorizados ao acesso dos recursos da União, que serão aqueles citados nos incisos I e II do parágrafo $1^{\circ}$ do artigo 18 , ou seja, os que:

Art. $18(\ldots)$

I. optarem por soluções consorciadas intermunicipais para a gestão dos resíduos sólidos, incluída a elaboração e implementação de plano intermunicipal, ou que se inserirem de forma voluntária nos planos microrregionais de resíduos sólidos referidos no $\S 1^{\text {ㅇ }}$ do art. $16 ; "$

II. implantarem a coleta seletiva com a participação de cooperativas ou outras formas de associação de catadores de materiais reutilizáveis e recicláveis formadas por pessoas físicas de baixa renda.

Para os municípios de pequeno porte, que se encontram em uma determinada região próxima, ainda cabe optar pelos consórcios públicos como uma forma de cumprir os requisitos do Plano Nacional de Resíduos Sólidos. Desta forma, os municípios alcançariam um nível maior de recursos financeiros e materiais, os quais não seriam possíveis de serem alcançados se cada um optasse por aderir ao Plano de forma isolada.

\section{CONSÓRCIOS MUNICIPAIS}

A implantação da Política Nacional de Resíduos Sólidos pelos municípios brasileiros deve gerar, de certa forma, grande empenho por parte dos entes públicos. Isso não é tarefa fácil, a partir do momento em que, além de necessitar de infraestrutura adequada para a disposição final dos resíduos sólidos, muitos dos municípios acabam por ter um custo muito alto pelo pouco que podem pagar.

Para solucionar esse problema, pode ser adotada a ideia de consórcios intermunicipais ou intergovernamentais. Trata-se de "associações voluntárias entre entes governamentais para produção e compartilhamento de valores públicos, requerendo cooperação entre as partes interessadas na realização de objetivos comuns" (MACHADO; ANDRADE, p. 1). Os consórcios são previstos no artigo 241 da Constituição Federal, que possui a seguinte redação:

Art. 241.- A União, os Estados, o Distrito Federal e os Municípios disciplinarão por meio de lei os consórcios públicos e os convênios de cooperação entre federados, autorizando a gestão associada de serviços

c) dos municípios de 10.001 até 20.000 habitantes, 31,8\% deles possuem um PGIRS; d) dos municípios de 20.001 até 50.000 habitantes, 36,7\% deles possuem um PGIRS; e) dos municípios de 50.001 até 100.000 habitantes, 46\% deles possuem um PGIRS; f) dos municípios de 100.001 até 500.000 habitantes, 46,9\% deles possuem um PGIRS; g) dos municípios de mais de 500.000 habitantes, $59 \%$ deles possuem um PGIRS. 
públicos, bem como a transferência total ou parcial de encargos, serviços, pessoal e bens essenciais à continuidade dos serviços transferidos.

Maria Sylvia Zanella Di Pietro explica qual é o objetivo da norma constitucional retro transcrita, qual seja o de "consolidar a gestão associada entre os entes federados para consecução de fins de interesse comum" além de frisar que geralmente "o serviço que uma pessoa jurídica pública não pode ou tem dificuldades para executar sozinha torna-se possível ou mais eficiente mediante a conjugação de esforços" (2015, p, 583, grifo da autora). Assim sendo, o custo investido para se realizar um consórcio público e se chegar aos objetivos pretendidos é menor do que o total de recursos que seriam necessários para que cada município, solitariamente, conseguisse chegar aos mesmos resultados pretendidos.

A Lei 11.107/2005, regulamentada pelo Decreto Federal 6.017/2007, normatizam a constituição dos consórcios públicos no Brasil, estabelecendo algumas etapas a serem obedecidas para que o ato do consórcio passe a ter efeitos. As etapas são:

a. estabelecer um protocolo de intenções;

b. ratificar este protocolo entre os entes federativos envolvidos;

c. estabelecer estatutos e um regimento interno;

d. formalizar um contrato de rateio;

e. por fim, estabelecer um contrato de programa (Decreto 6.017/07, Art. $2^{\circ}$, III, IV e VII).

Como bem explica Ângelo Marcos Queiróz Prates, os consórcios necessariamente precisarão de um fundo para realizar a sua missão e, para isso, os entes participantes do consórcio podem contribuir com parte de suas receitas correntes e também arrecadar receitas a partir dos serviços prestados. Todos estes recursos resultantes do consórcio serão fortemente controlados através da fiscalização do Tribunal de Contas, assim como de toda a sociedade civil envolvida. É válido ressaltar também que, os municípios que participarem de consórcios municipais encontram-se dispensados da elaboração dos seus próprios Planos Municipais de Gestão Integrada de Resíduos Sólidos (2010, p. 7).

Ainda, segundo análise feita pelo supracitado autor a respeito de pesquisas realizadas pelo IBGE de 2007, dentre as grandes regiões brasileiras, aquela que mais possui consórcios intermunicipais com a finalidade de aderir ao Plano de Gestão Integrada de Resíduos Sólidos é a região Sul, com 133 municípios consorciados; seguida da região Sudeste, com 99 municípios consorciados; após vem a região Nordeste, com 83 municípios componentes de consórcios; a 
região Norte, com 15 municípios consorciados e, por fim, a região Centro-Oeste, com apenas 13 municípios consorciados (PRATES, 2010, p. 15).

Diante disso, deve ser considerada a dificuldade de municípios de pequeno porte com recursos financeiros e estruturas escassas no momento de adoção do Plano de Resíduos Sólidos, pois é a partir desta análise de cada municipalidade que surgem as grandes parcerias para concretizar obras, atividades e serviços que, por hora, seriam de competência local, porém, são de grande importância para o interesse comum de determinada região.

\section{CONCLUSÃO}

Avaliou-se com este artigo, do ponto de vista jurídico, a realidade do meio ambiente brasileiro protegido pela Constituição Federal de 1988, explanado como um direito fundamental que, infelizmente, não está recebendo a adequada atenção. Foi com a Constituição Federal de 1988 - conhecida também como Constituição Verde - que se positivou expressamente o direito ao meio ambiente sustentável, pensando não somente nas presentes gerações, mas também nas gerações que estão por vir, e que também merecem um meio ambiente adequado e uma sadia qualidade de vida. A criação do Estatuto da Cidade contribuiu, e muito, para a efetividade deste direito fundamental, pois é a Lei $n^{\circ} 10.257$ de julho de 2001 que regulamentou os artigos da Constituição que se referem ao meio ambiente ecologicamente equilibrado nas cidades brasileiras. O Estatuto alerta sobre a importância de um Plano Diretor eficiente, que colabore para o correto uso do solo urbano dos municípios brasileiros, sempre com vista ao bem-estar coletivo, a segurança e um meio ambiente saudável.

A Política Nacional de Resíduos Sólidos (PNRS) prevê que todos os municípios elaborem os seus Planos de Gestão Integrada de Resíduos Sólidos (PGIRS) e contribuam, dessa forma, para atingir os fins da Política nas mais diversas partes do país. Observou-se no corpo do artigo que grande parte das municipalidades brasileiras já elaboraram seus planos, de forma isolada ou consorciada, sendo esta última uma solução para a falta de estrutura e escassez financeira dos diferentes municípios situados no País e incluídos na área de abrangência da PNRS.

Desta forma, cabe salientar que, a partir do momento que cada um (pessoas, sociedade, empresas, municípios, estados, regiões e país) faz a sua parte, será possível combater a desenfreada produção e má destinação dos resíduos sólidos, pois a realidade é adversa, e a única saída é a união de todos com um objetivo comum, qual seja ele, o de adquirir uma vida saudável e garantir um futuro sustentável para os descendentes desta nação, com 
padrões de consumo moderados e de acordo com as capacidades do meio ambiente em questão.

\section{REFERÊNCIAS}

ABNT. Associação Brasileira de Normas Técnicas. Disponível em: http://www.abnt.org.br/. Acesso em 05 abr. 2017.

Barragem se rompe, e enxurrada de lama destrói distrito de Mariana. Portal G1. São Paulo, 05 nov. 2015. Disponível em: http://g1.globo.com/minas-gerais/noticia/2015/11/barragem-derejeitos-se-rompe-em-distrito-de-mariana.html. Acesso em 05 abr. 2017.

BRASIL, Lei 12.305, de 02 de agosto de 2010. Institui a Política Nacional de Resíduos Sólidos; altera a Lei no 9.605, de 12 de fevereiro de 1998; e dá outras providências. Disponível em: http://www.planalto.gov.br/ccivil_03/_Ato2007-2010/2010/Lei/L12305.htm. Acesso em 21 jan. 2017.

Lei 10.257 , de 10 de julho de 2001. Regulamenta os artigos 182 e 183 da Constituição Federal, estabelece diretrizes gerais da política urbana e dá outras providências. Disponível em: https://www.planalto.gov.br/ccivil_03/Leis/LEIS_2001/L10257.htm. Acesso em 21 jan. 2017.

ABNT NBR 10004:2004. Resíduos Sólidos: classificação. 30 nov. 2004. Disponível em: http://www.abntcatalogo.com.br/norma.aspx?ID=936. Acesso em 21 jan. 2017.

Constituição (1988). Constituição da República Federativa do Brasil. Brasília, DF: Senado Federal: Centro Gráfico, $1988 . \quad$ Disponível em: https://www.planalto.gov.br/ccivil_03/Constituicao/Constituicao.htm. Acesso em 21 jan. 2017.

Decreto $n^{\circ}$ 6.017, de 17 de janeiro de 2007. Regulamenta a Lei no 11.107, de 6 de abril de 2005, que dispõe sobre normas gerais de contratação de consórcios públicos. Disponível em http://www.planalto.gov.br/ccivil_03/_Ato2007-2010/2007/Decreto/D6017.htm. Acesso em: 21 jan. 2017.

IBGE. Tabela 67: Municípios, total e com Plano de Gestão Integrada de Resíduos Sólidos, nos termos estabelecidos na Política Nacional de Resíduos Sólidos, segundo as Grandes Regiões e as classes de tamanho da população dos Municípios. 2013. Disponível em: ftp://ftp.ibge.gov.br/Perfil_Municipios/2013/pdf/tab67.pdf. Acesso em mai. 2016.

Lei 11.107, de 06 de abril de 2005. Dispõe sobre normas gerais de contratação de consórcios públicos e dá outras providências. Disponível em: https://www.planalto.gov.br/ccivil_03/_Ato2004-2006/2005/Lei/L11107.htm. Acesso em 21 jan. 2017.

Lei 11.445 , de 05 de janeiro de 2007. Estabelece diretrizes nacionais para o saneamento básico; altera as Leis nos 6.766, de 19 de dezembro de 1979, 8.036, de 11 de maio de 1990, 8.666, de 21 de junho de 1993, 8.987, de 13 de fevereiro de 1995; revoga a Lei no 6.528, de 11 de maio de 1978; e dá outras providências. Disponível em: http://www.planalto.gov.br/ccivil_03/_Ato2007-2010/2007/Lei/L11445.htm. Acesso em 21 jan. 2017.

Lei 6.938, de 31 de agosto de 1981. Dispõe sobre a Política Nacional do Meio Ambiente, seus fins e mecanismos de formulação e aplicação, e dá outras providências. Disponível em: http://www.planalto.gov.br/Ccivil_03/Leis/L6938.htm. Acesso em 21 jan. 2017.

Sólidos.

Ministério do Meio Ambiente. Guia para Elaboração dos Planos de Gestão dos Resíduos
Brasília:
2011b.
Disponível
em: 
http://www.mma.gov.br/estruturas/srhu_urbano/_arquivos/guia_elaborao_plano_de_gesto_d e_resduos_rev_29nov11_125.pdf. Acesso em mai. 2016.

Ministério do Meio Ambiente. Inclusão Social de Catadores. Disponível em: http://www.mma.gov.br/responsabilidade-socioambiental/a3p/eixos-tematicos/item/9341.

Acesso em 21 jan. 2017.

MINISTÉRIO DO MEIO AMBIENTE. Plano Nacional de Resíduos Sólidos. Brasília: 2011a.

Disponível em: http://www.mma.gov.br/estruturas/253/_publicacao/253_publicacao02022012041757.pdf. Acesso em mai. 2016.

CARVALHO, Flávia Gualtieri de [et al] (Orgs.) Guia Nacional de Licitações Sustentáveis. Brasília: AGU, 2016. Disponível em: www.agu.gov.br/page/download/index/id/33743204. Acesso em 21 jan. 2017.

CONAMA - Conselho Nacional do Meio Ambiente. Resolução $n^{\circ} 01$ de 1986. Dispõe sobre critérios básicos e diretrizes gerais para a avaliação de impacto ambiental. Disponível em: http://www.siam.mg.gov.br/sla/download.pdf?idNorma=8902. Acesso em 21 jan. 2017.

COSTA, Edmilson Rodrigues da. Uma Visão Comentada da Lei da PNRS. Disponível em: http://www.revistapetrus.com.br/uma-visao-comentada-sobre-a-lei-da-pnrs/. Acesso em 10 mai. 2016.

DI PIETRO, Maria Sylvia Zanella. Direito Administrativo. São Paulo: Atlas, 2015.

FREITAS, José Carlos de. O Estatuto da Cidade e o Equilíbrio do Espaço Urbano. Ministério Público do Estado de Minas Gerais. Seção Artigos. Disponível em: http://wwwantigo.mpmg.mp.br/portal/public/interno/repositorio/id/4325. Acesso em 10 mai. 2016.

GRASSI, Fiorindo Davi. Direito Ambiental Aplicado. Frederico Westphalen: URI, 1995.

Ilhas de plástico matam 1,5 milhão de animais por ano, diz especialista. UOL Notícias. São Paulo, 17 out. 2014. Disponível em: https://noticias.uol.com.br/ciencia/ultimasnoticias/afp/2014/10/17/ilhas-de-plastico-matam-15-milhao-de-animais-por-ano-dizespecialista.htm. Acesso em 05 abr. 2017.

LEFF, Enrique. Saber ambiental: sustentabilidade, racionalidade, complexidade, poder. Petrópolis: Vozes, 2011.

MACHADO, José Angelo; ANDRADE, Marta Leone Costa. Cooperação intergovernamental, consórcios públicos e sistemas de distribuição de custos e benefícios. Revista de Administração Pública, Rio de Janeiro, v. 48, n. 3, p. 695-720, jun. 2014. Disponível em $<$ http://www.scielo.br/scielo.php?script=sci_arttext\&pid=S0034-

76122014000300008\&lng=pt\&nrm=iso>. Acesso em: 05 abr. 2017. http://dx.doi.org/10.1590/0034-76121626.

MACHADO, Paulo Affonso Leme. Princípios da Política Nacional de Resíduos Sólidos. Revista do Tribunal Regional Federal da 1. Região. v. 24, n. 7, jul. 2012. Disponível em: http://bdjur.stj.jus.br/jspui/bitstream/2011/49748/principios_politica_nacional_machado.pdf. Acesso em 10 mai. 2015. 
MARTINE, George; ALVES, José Eustáquio Diniz. Economy, society and environment in the 21st century: three pillars or trilemma of sustainability? Revista Brasileira de Estudos Populacionais, São Paulo, v. 32, n. 3, p. 433-460, dez. 2015. Disponível em: $<$ http://www.scielo.br/scielo.php?script=sci_arttext\&pid=S010230982015000300433\&lng=pt\&nrm=iso>. Acesso em: 05 abr. 2017. Epub 13-Nov-2015. http://dx.doi.org/10.1590/\$0102-3098201500000027.

PRATES, Ângelo Marcos Queiróz. Os Consórcios Públicos Municipais no Brasil e a Experiência Europeia: alguns apontamentos para o desenvolvimento local. III Congresso Consad de Gestão Pública. $2010 . \quad$ Disponível em http://repositorio.fjp.mg.gov.br/consad/bitstream/123456789/381/1/C3_TP_OS\%20CONS\%C3 \%93RCIOS\%20P\%C3\%9ABLICOS\%20MUNICIPAIS\%20NO\%20BRASIL\%20E\%20A\%20EXPERI\%C3\% 8ANCIA.pdf Acesso em 14/05/2016.

ROUSSEAU, Jean-Jacques. Discurso sobre a origem da desigualdade. São Paulo: Ridendo Castigat Mores, 2001. Disponível em: http://www.ebooksbrasil.org/adobeebook/desigualdade.pdf. Acesso em abr. 2016.

SANTIN, Janaína Rigo. O Estatuto da Cidade e a Gestão Democrática Municipal. Revista Interesse Público, Porto Alegre, ano 5, n. 21, p. 220-229, set./out. 2003.

SANTIN, Janaína Rigo; LEIDENS, Letícia Virgínia. Plano Diretor: instrumento de efetivação da função social da propriedade urbana e participação popular. Revista Brasileira de Direito Municipal, n. 20, ano 7, Belo Horizonte, p. 25-41, abr./jun. 2006.

SANTIN, Janaína Rigo; SIGNOR, Paola Bortoluz. Usucapião especial coletiva urbana e direito à moradia: em defesa da regularização fundiária das cidades e metrópoles brasileiras. In: RECH, Adir Ubaldo; COIMBRA, Diego. A Cidade: uma construção interdisciplinar. Caxias do Sul: Educs, 2016. Disponível em: https://www.ucs.br/site/midia/arquivos/ebook-a-cidade.pdf. Acesso em 21 jan. 2017.

SANTIN, Janaína Rigo; SANTOS, Mariana Mattei. Plano diretor e patrimônio histórico: análise a partir da Constituição Federal de 1988 e do Estatuto da cidade. Revista Direito da Cidade, v. 8, n. 2, 2016. Disponível em: http://www.e-publicacoes.uerj.br/index.php/rdc/article/view/20295. Acesso em 21 jan. 2017.

SILVA, Carlos Sérgio Gurgel da. Política Urbana Brasileira: em busca de cidades sustentáveis. Jus Navigandi, mar. 2013. Disponível em: https://jus.com.br/artigos/23856/politica-urbanabrasileira-em-busca-de-cidades-sustentaveis. Acesso em 10 mai. 2016.

SILVA, José Afonso da. Direito ambiental constitucional. 5. ed. São Paulo: Malheiros, 2004.

Tragédia ambiental no golfo do México completa 50 dias, e dimensão do desastre só aumenta. UOL Notícias. São Paulo, 09 jun. 2010. Disponível em: https://noticias.uol.com.br/internacional/ultimas-noticias/2010/06/09/tragedia-ambiental-nogolfo-do-mexico-completa-50-dias-e-dimensao-do-desastre-so-aumenta.htm. Acesso em 05 abr. 2017. 
Trabalho enviado em 21 de janeiro de 2017. Aceito em 06 de abril de 2017. 